\title{
Interdisciplinary Studies Integrating The Black Sea Biogeochemistry and Circulation Dynamics
}

\author{
Temel Oguz \\ Middle East Technical University · Icel Turkey
}

\author{
Paola Malanotte-Rizzoli \\ Massachusettes Institute of Technology • Cambridge, Massachusetts USA
}

\author{
Hugh W. Ducklow \\ Virginia Institute of Marine Sciences, The College of William and Mary \\ Gloucester Point, Virginia USA
}

James W. Murray

University of Washington - Seattle, Washington USA

The Black Sea is a deep (about $2 \mathrm{~km}$ ) elliptic basin with zonal and meridional dimensions of approximately $1000 \mathrm{~km}$ and approximately $400 \mathrm{~km}$, respectively, located roughly between $28^{\circ}$ and $42^{\circ} \mathrm{E}$ longitudes, $41^{\circ}$ and $46^{\circ} \mathrm{N}$ latitudes (Figure 1). It has only a narrow opening to the shallow ( $<75 \mathrm{~m}$ deep) Bosphorus Strait; otherwise, it is a completely enclosed marginal sea. Until the early 1970s, the Black Sea consisted of a mosaic of diverse ecosystems that provided a vital habitat for many commercial species. It supported fisheries almost five times richer than those of neighboring Mediterranean. Then, it has been gradually transformed into a severely degraded marine habitat suffering from the introduction of large volumes of nutrients and contaminants from the Danube River and others along the northwestern coast (Mee, 1992). The state of the ecosystem after the mid-1970s reflected severe environmental deterioration, intense eutrophication, dramatic decreases in biodiversity and fish stocks, especially in the northwestern shelf and the Sea of Azov (Zaitsev and Mamaev, 1997).

The long-term massive fertilization of the sea by nutrients from domestic, agricultural and industrial sources has caused a substantial modification of the phytoplankton community structure and succession, as well as an increase in the intensity, frequency and expansion of microalgal blooms. The total phytoplankton biomass has increased by an order of magnitude along the western coast, and about 3-4 times within the interior. Individual blooms have been documented as becoming more and more monospecific. From the food web point of view, the eutrophic Black Sea ecosystem has been producing more biomass than it used to three to four decades ago. But its taxonomic composition has changed, and is mostly dominated by opportunistic species and gelatinous carnivores acting as top predators and deadend of the food chain. Total biomass of mesozooplankton species was decreased by a factor of five, while the abundance of opportunistic species (Noctiluca, Pleurobrachia, jelly fish Aurelia aurita, and ctenophore Mnemiopsis leidyi) reached $90 \%$ of the total zooplankton wet weight (Vinogradov et al., 1999; Kideys et al., 2000). First, Aurelia during the late 1970s and 1980s, and later Mnemiopsis during the late 1980s consumed almost all zooplankton groups, which were essential components in the marine food web. Because Aurelia and Mnemiopsis had no predators in the Black Sea, their communities quickly dominated the entire ecosystem, and changed its structure and, together with overfishing, contributed to the collapse of the fishery in the late 1980s. The situation has become so severe that it has affected the health, well-being and standard of living of nearly 160 million people in the region. Economic losses exceeded $\$ 500$ million per year, as estimated by the World Bank.

The sharp density stratification, accompanied with weak vertical circulation and mixing as well as limited lateral influxes, inhibit ventilation of sub-pycnocline waters of the Black Sea from the surface. Organic matter, continually sinking and decomposing, has thus led to development of a permanent anoxia and high concentrations of hydrogen sulfide below a depth of $100-150 \mathrm{~m}$ during approximately the last 7000 years. The Black Sea vertical biogeochemical structure thus differs significantly from its typical oceanic counterparts. The complex prey-predator interactions between different phytoplankton and zooplankton groups are tightly linked with a very efficient remineralization- 


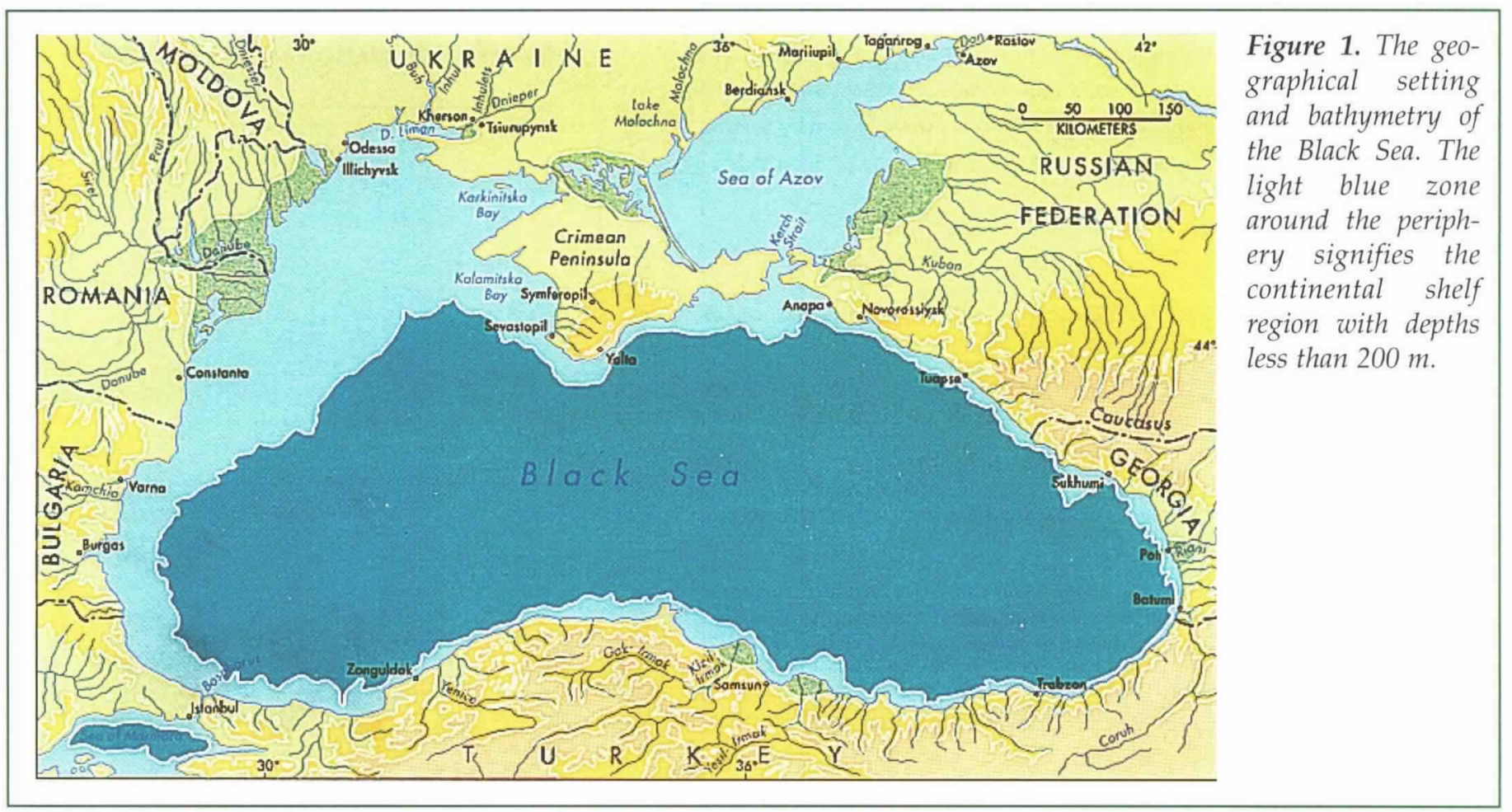

ammonification-nitrification-denitrification chain, and a series of different types of highly complex bacteriallymediated oxidation-reduction reactions controlling the structure and dynamics of the suboxic-anoxic transition zone. The biogeochemical pump operates within the uppermost $100 \mathrm{~m}$ of the water column. The euphotic zone structure, covering maximally the uppermost $50 \mathrm{~m}$ (approximately), is characterized by high oxygen concentrations on the order of $300 \mu \mathrm{M}$, and a yearround biological activity. The underlying $20-30 \mathrm{~m}$ layer contains steep gradients in chemical properties where particle remineralization causes considerable reduction in oxygen concentration to the values of approximately $10 \mu \mathrm{M}$, whereas nitrate increases to maximum concentrations of 6-9 $\mu \mathrm{M}$ (Codispoti et al., 1991). The subsequent Suboxic Layer (SOL) of about $20-40 \mathrm{~m}$ is characterized by oxygen concentrations less than $10 \mu \mathrm{M}$, rapid decrease of nitrate concentrations to zero due to the consumption in organic matter decomposition (Murray et al., 1989). Below the SOL, sulfate is used to decompose organic matter, and hydrogen sulfide is produced as a byproduct. The loss to the deep anoxic layer is not more than $10 \%$ of the total particulate material remineralized, and is compensated by the riverine input. This highly delicate and efficient system maintains the current quasi-stable nature of the vertical biogeochemical structure of the Black Sea, thus preventing the upward rise of the sub-surface sulfidic waters. The upper boundary of the SOL, however, seems to have moved to shallower depth since the 1960s, as reported by Konovalov and Murray (2001).

All these distinct features make the Black Sea a unique example for studying an array of natural and human impacts on a continuously changing (on decadal time scale) perturbed ecosystem and on biogeochemical structures. When combined with its highly energetic mesoscale-dominated circulation and complex shelf-deep basin interactions, they make the Black Sea an excellent natural arena for testing capabilities and performances of interdisciplinary models. During the 1990s, the major question confronted by the riparian countries was to identify the measures needed to stop its further deterioration. In order to prepare the scientific basis to address the environmental and socioeconomic issues facing the Black Sea, some observational and modeling efforts have been performed within the framework of several international programs. As a part of these efforts, we have undertaken a series of modeling studies devoted ultimately to exploring, quantifying, and predicting circulation, ecosystem and biogeochemical variability from the overall basin scale to coastal/shelf domains, and over time scales extending from weeks to seasons. Here, we present an overview of our recent progress achieved on: (i) a unified dynamical description of the pelagic food web and vertical biogeochemical structure via coupling of its major processes and interactions between the oxic, suboxic and anoxic layers, and; (ii) identifying impacts of the circulation dynamics on biogeochemical transports.

\section{Modeling the Food Web and Biogeochemical Pump}

Constructing a mathematical framework for studying interdecadal transformations of the Black Sea ecosystem and biogeochemistry is a challenge. It requires dealing with a complex set of interactions between key autotrophic, heterotrophic and carnivore 


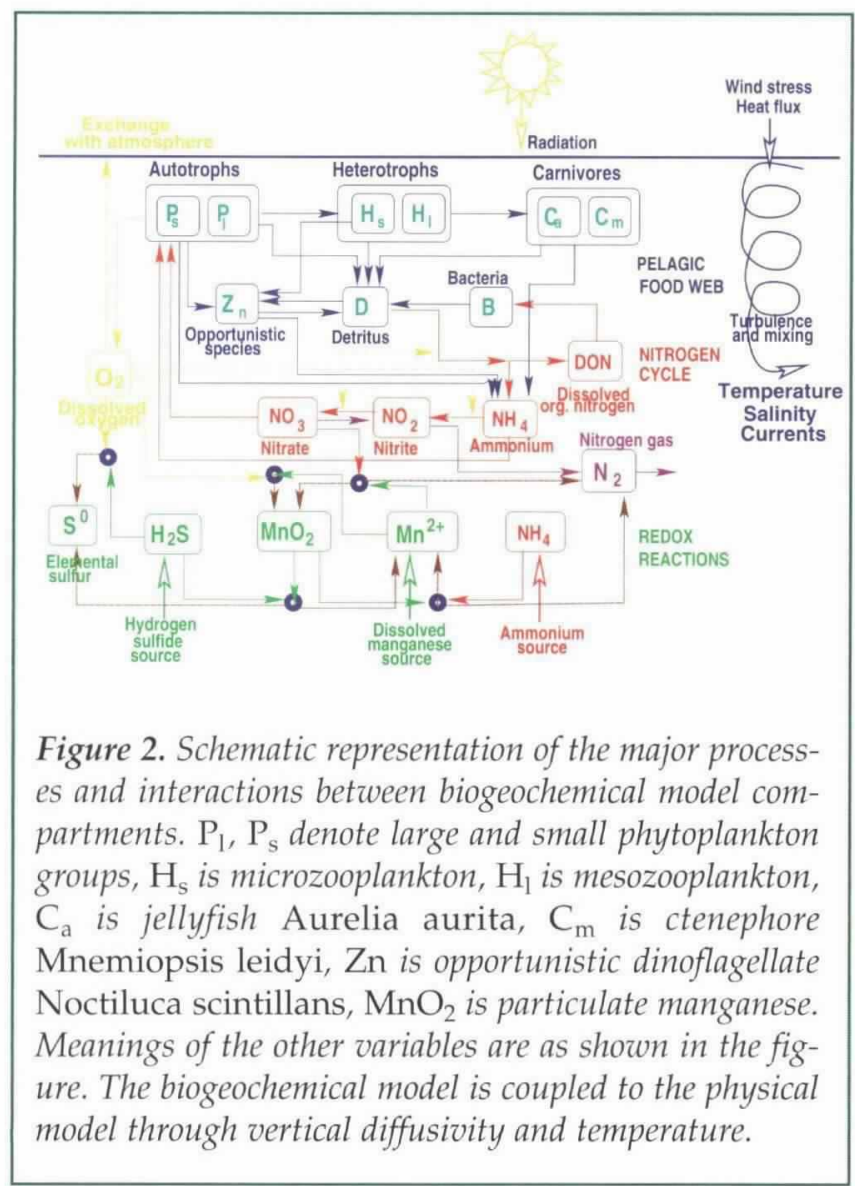

species and/or groups at different periods of the temporally-changing ecosystem. Our modeling initiative started at the mid-1990s with a one-dimensional, vertically-resolved (with approximately a $3 \mathrm{~m}$ grid spacing), five compartment biological model coupled with upper ocean physics and the Mellor-Yamada order 2.5 turbulence mixing parameterization (Oguz et al., 1996). This model has then been elaborated by introducing sophistications, as well as carrying out extensive sensitivity, calibration and validation studies for the food web (Oguz et al., 1999; 2001a), the nitrogen and redox cycles (Oguz et al., 2001b; Oguz, 2002), and the water column oxygen dynamics (Oguz et al., 2000).

The main features of the biogeochemical model, which provides a unified description of the pelagic food web, nitrogen cycle and oxidation-reduction reactions, are summarized in Figure 2. The food web structure comprises two groups of phytoplankton (diatoms and phytoflagellates), two classes of herbivorousomnivorous zooplankton (microzooplankton and mesozooplankton), nonphotosynthetic free living bacterioplankton, medusae Aurelia aurita and ctenophore Mnemiopsis leidyi, as well as the opportunistic omnivorous dinoflagellate Noctiluca scintillans. These microbial and herbivorous-carnivorous food web structures are coupled through particulate and dissolved organic material fluxes to transformations among organic and inorganic (nitrate, nitrite and ammonium) forms of dissolved nitrogen. They are further linked with a

\section{Aurelia-dominated Ecosystem}
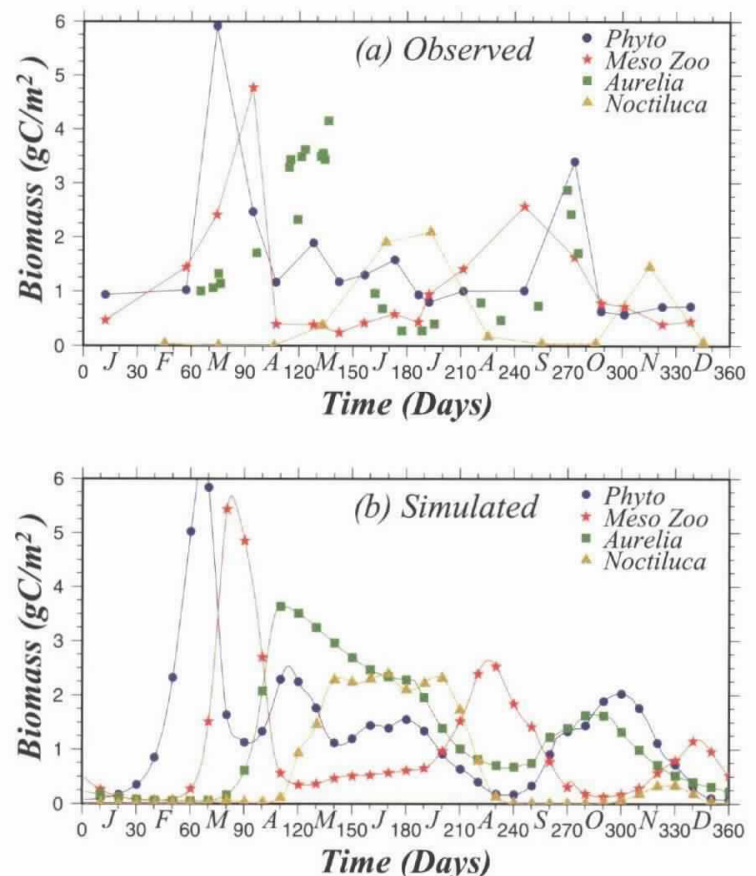

Figure 3. (a) Observed, and (b) simulated annual distributions of total phytoplankton, mesozooplankton, Noctiluca, and Aurelia biomass for the eutrophic, Aurelia-dominated (pre-Mnemiopsis) phase of the ecosystem. The data for phytoplankton and mesozooplankton biomass are taken from measurements carried out at 2-4 weeks intervals during January-December 1978 at a station, off Gelendzhik along the Caucasian coast. The Noctiluca and Aurelia biomass data are taken from measurements on the Romanian shelf and the interior basin, respectively, during the late 1970s and early 1980s (after Oguz et al., 2001a).

model of oxygen and redox dynamics based on a set of oxygen, nitrogen and sulfur reactions coupled with the manganese cycle, as suggested by Murray et al., (1995). Hydrogen sulfide, elemental sulfur, dissolved oxygen, dissolved and particular manganese constitute the main elements of the redox model (Oguz et al., 2001b). When dissolved oxygen is available, it oxidizes particulate organic material and hydrogen sulfide, ammonium, and dissolved manganese transported upwards from deeper levels. In oxygen depleted waters, dissolved oxidized manganese reacts with nitrate to produce settling particulate oxidized manganese and nitrogen gas. Hydrogen sulfide and ammonium are then oxidized by particulate oxidized manganese to locally form elemental sulfur, nitrogen gas and dissolved manganese. Elemental sulfur is reduced back to hydrogen sulfide by bacteria; nitrogen gas escapes to the atmosphere, and dissolved manganese is reoxidized by nitrate. 


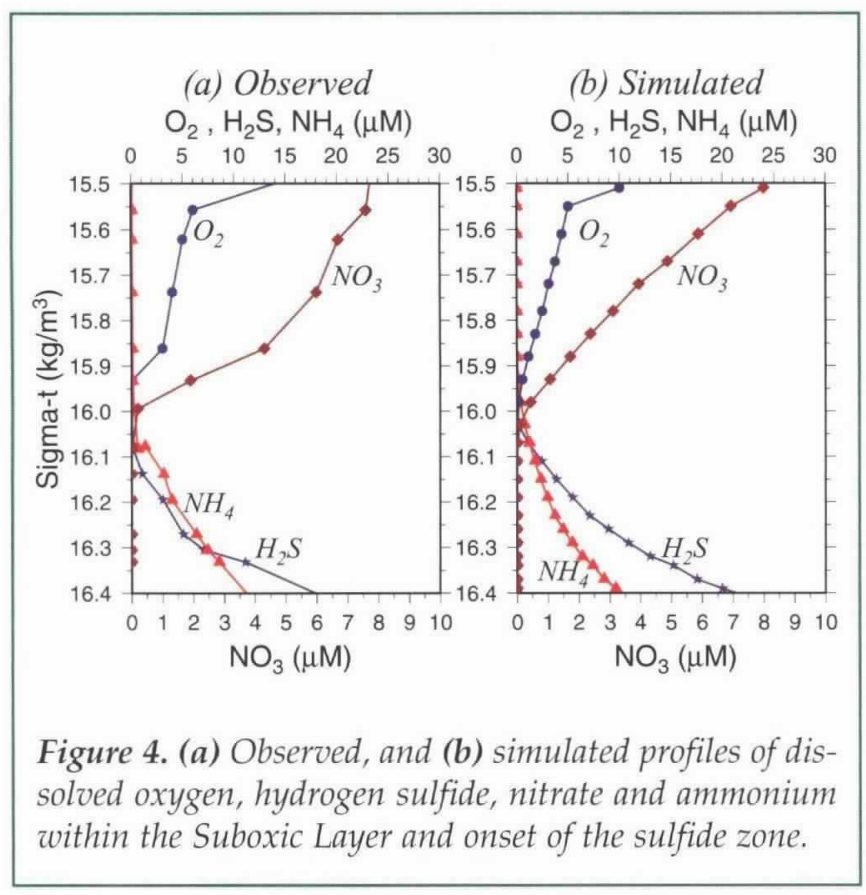

A set of model simulations demonstrated how the simultaneous controls imposed by bottom-up forcing associated with anthropogenic-based nutrient enrichment and top-down grazing pressure introduced by gelatinous predators on mesozooplankton could lead to the changes in functioning of the Black Sea ecosystem during its transformation from a healthy state in the 1960s to a eutrophic state in the 1980s (Oguz et al., 2001a). Much smaller and almost uniform plankton distributions characterized the unperturbed ecosystem for most of the year. The increased anthropogenic nutrient load (bottom-up control) together with population explosions in medusa Aurelia during the 1970s and 80 s (top-down control) were shown to lead to practically uninterrupted phytoplankton blooms and a major reduction in microzooplankton and omnivorous mesozooplankton biomass (Figure 3). The major bloom event of the year took place during late winter to early spring as a consequence of nutrient accumulation in the surface waters at the end of the winter mixing season. This was followed by two successive and longer events during spring-early summer, and autumn. The early spring bloom was followed first by a mesozooplankton bloom of comparable intensity, which reduced the phytoplankton stock to a relatively low level, and then by an Aurelia bloom that similarly grazed down the mesozooplankton. The phytoplankton recovered and produced a weaker late spring bloom, which triggered a steady increase in Noctiluca biomass during the mid-summer. As the Aurelia population decreased in August, first mesozooplankton and then phytoplankton, Noctiluca and Aurelia gave rise to successive blooms during September-November period.

Increases of the biomass of the ctenophore Mnemiopsis leidyi led to even more pronounced and longer-lasting phytoplankton blooms due to stronger top-down control introduced into the ecosystem during the late 1980s and 90s. The resulting plankton distribution possesses three successive bloom events during winter, spring and summer. An intense winter phytoplankton bloom emerged as a new feature of the annual phytoplankton structure after Mnemiopsis colonization. It is, in fact, a modified version of the late winter event of the pre-Mnemiopsis era, shifted as a consequence of the particular form of grazing pressure exerted by Mnemiopsis, which almost completely depleted the microzooplankton, and Noctiluca stocks toward the end of autumn season. The lack of grazing pressure on the phytoplankton community then promoted earlier growth starting by the beginning of January. Winter blooms with that intensity were not reported until 1990s, but were persistently observed in both satellite and in situ data during the 1990s (Yilmaz et al., 1998; Oguz et al., 2002). The other two blooms may also be interpreted as the modified forms of late spring to early summer and autumn events.

Almost continuous particulate organic matter production associated with the year-long biological activity supports an efficient nitrogen cycling within approximately the upper $75 \mathrm{~m}$ of the water column, where dissolved oxygen generated photosynthetically and by air-sea interactions is depleted due to consumption during aerobic particulate matter decomposition (Oguz et al., 2000). The layer below could not be ventilated even for the conditions of exceptionally high winter cooling due to the presence of a strong density stratification. Even with a highly simplified representation of the redox processes, the model provided a quasisteady state suboxic-anoxic interface zone structure similar to observations (Figure 4). It was able to give quantitative evidence for the presence of an oxygen depleted and non-sulfidic suboxic zone. This model pointed out the crucial role of the downward supply of nitrate from the overlying nitracline zone and the upward transport of dissolved manganese from the anoxic pool below for maintenance of the suboxic layer. The model is also used to test the assumption of isopycnal homogeneity of the SOL properties and their independence from the circulation features, as asserted previously (Tugrul et al., 1992). It is found that the SOL properties do not possess isopycnal uniformity throughout the basin, and vary depending on the intensity of vertical diffusive and advective oxygen fluxes across the oxycline (Oguz, 2002). Anticyclones, with downwelling and downward diffusion (i.e., with stronger net downward supply of oxygen), attain a thinner suboxic layer at a deeper part of the water column relative to cyclones. The position of the upper boundary of the SOL changes from $\sigma_{\mathrm{t}} \sim 15.6 \mathrm{~kg} \mathrm{~m}^{-3}$ in cyclonic to $15.9 \mathrm{~kg} \mathrm{~m}^{-3}$ in anticyclonic regions, whereas its position in the peripheral Rim Current transition zone occurs at intermediate density values. Re-analysis of the existing data provides firm evidence for such differences. 


\section{Features of the Circulation Field}

Our conception of the Black Sea circulation has had significant progress during the last decade through realization of several basin-wide, multi-ship field campaigns, complemented by different types of satellite data. When compared with the classical concept of the twin-gyre circulation inferred from the coarse resolution hydrographic data, the circulation deduced by the recent medium resolution synoptic surveys (Oguz et al., 1994; Oguz and Besiktepe, 1999; Besiktepe et al., 2001) and satellite imagery (Oguz et al., 1992; Sur et al., 1994; Korotaev et al., 2001) indicated a mesoscaledominated circulation system superimposed on the quasi-permanent basin and sub-basin scale elements. The building blocks of the upper layer circulation are identified as the Rim Current system around the periphery, an interior cell involving different types of structural organizations from two sub-basin scale cyclonic gyres to a series of interconnected large mesoscale cyclonic eddies, and some quasistable/recurrent anticyclonic eddies on the coastal side of the Rim Current. This system of circulation is further accompanied by meanders, filaments, offshore jets as well as cyclonically propagating highly transient features of the Rim Current.

Common to all data sets is the bi-modal character of the circulation during the year. The winter circulation is persistently dominated by a two cyclonic gyre system in the western and eastern basins, encircled by a weakly meandering, organized and strong Rim Current jet (Figure 5a). During the spring and summer seasons, this system transforms into one composite basin-wide cyclonic cell comprising multi-centered cyclonic eddies, surrounded by a weaker but broader and more variable Rim Current zone (Figure 5b). During the autumn, the upper layer circulation attains its most disorganized form, identified by a series of cyclonic eddies within the interior cell and accompanying pronounced lateral variabilities and larger coastal anticyclonic eddies around the periphery. A composite cyclonic peripheral Rim Current circulation is hardly identified during this period. On the other hand, the northwestern shelf exhibits a highly variable and dynamic circulation structure throughout the year. It is formed by a combination of the Danube outflow, wind stress forcing and the Rim Current structure of the basin-wide circulation system along its offshore side. The southward direction of the coastal current emerges as the predominant path of the fresh water-induced flow regime within the inner shelf along the west coast. It may be deflected occasionally northward towards the upstream, and forms an anticyclonic circulation cell confined within the northern part of the shelf. The southward coastal flow largely diminishes under such cases. Moreover, the outer flank of shelf flow system often has an unstable structure; it exhibits meanders, spawns filaments toward the wide topographic slope zone, and is also modulated by on-shelf intrusions of
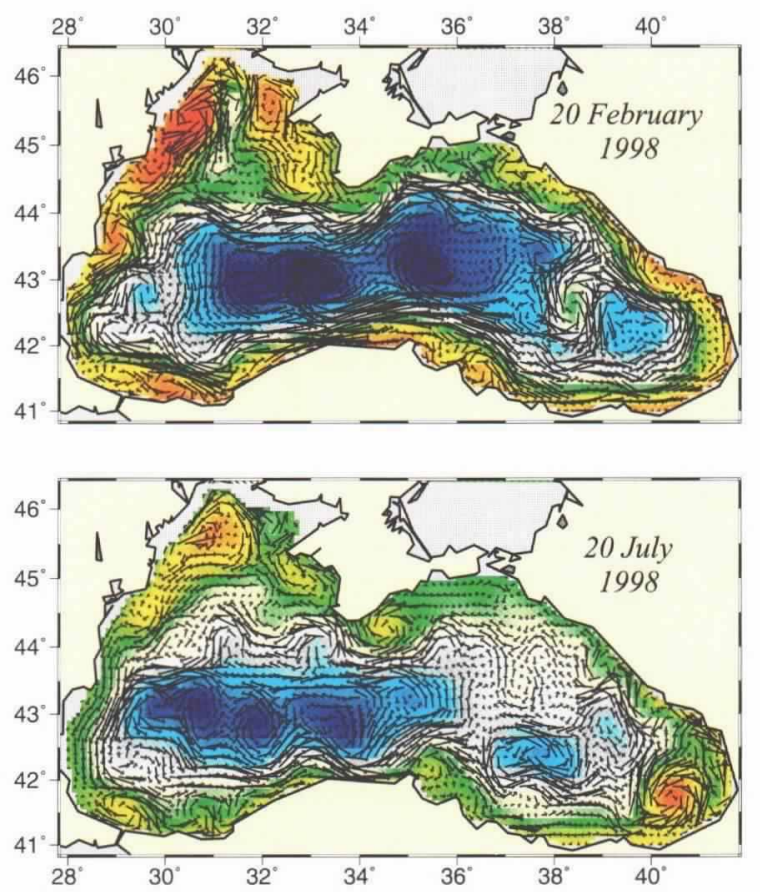

Figure 5. The upper layer circulation pattern for (a) February 1998, (b) July 1998, shown as examples of the winter and summer horizontal flow structures, respectively. They are derived by assimilation of the TopexPoseidon and ERS altimeter data into a 1.5 layer reducedgravity model. The background colors show the corresponding sea level anomaly patterns given by the altimeter data.

the Rim Current meanders. The nearly four year time series of the SeaWIFS chlorophyll data from September 1997 to the end of December 2000 provides examples of various forms of the northwestern shelf circulation and its mesoscale and sub-mesoscale structures (Oguz et al., 2002).

\section{Role of Circulation on Biogeochemical Transports}

The SeaWiFS images also suggest evidence for a close link between biological production along the Anatolian coast and on the northwestern shelf (Oguz et al., in press). The Anatolian coastal waters are shown to support production during most parts of the year as long as they receive sufficient nutrient supply from the northwestern shelf through the coastal current system as in the spring-summer 1999 (Figure 6). The offshore meanders and filaments of the Rim Current system supply part of this production into the interior of the basin. Thus, in addition to vertical processes (entrainment, diffusion, upwelling), the interior basin production within the mixed layer can be maintained or enhanced by lateral advective transports as well. At times, when the fresh water induced coastal flow is 


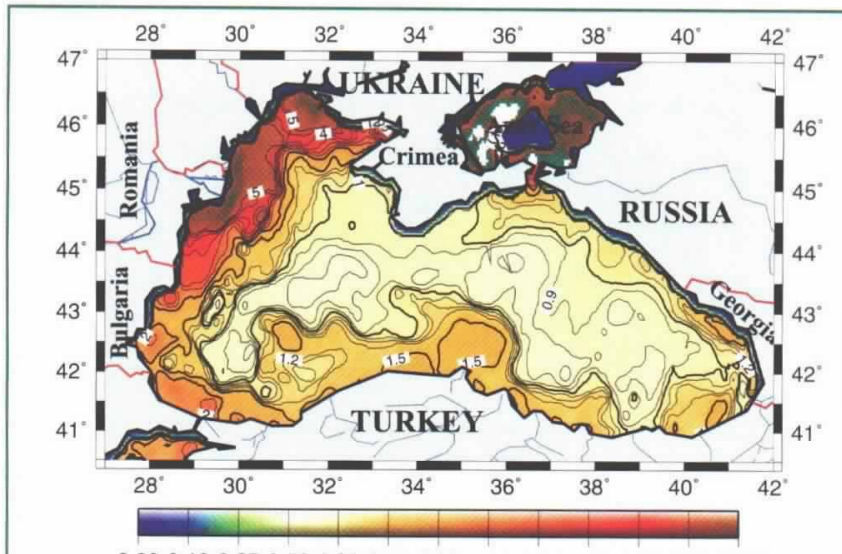

0.000 .100 .250 .501 .001 .502 .002 .503 .003 .504 .005 .0010 .00 $\mathrm{Chl}\left(\mathrm{mg} \mathrm{m}^{-3}\right)$

Figure 6. Monthly composite SeaWiFS image of the surface chlorophyll concentration (in $m g \mathrm{~m}^{-3}$ ) for August 1999.

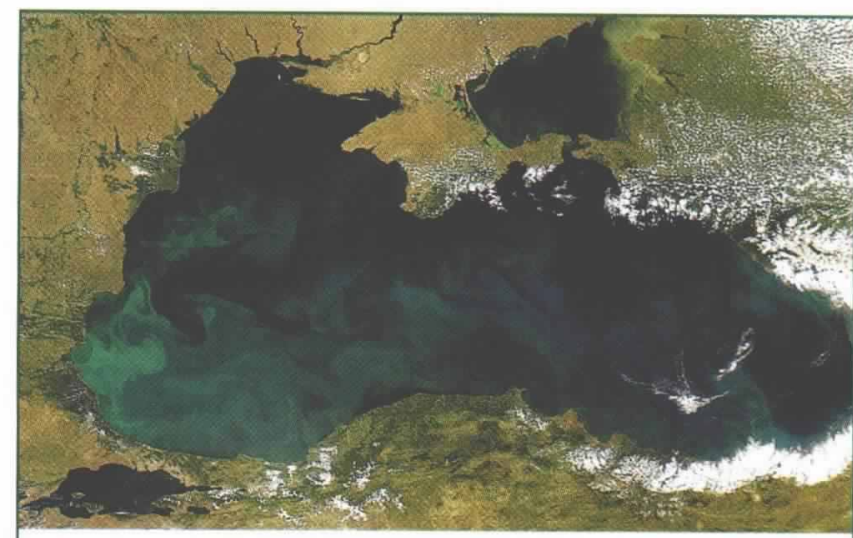

Figure 7. SeaWiFS true color image on 16 June 2000. The turquoise color covering the Sea of Marmara and majority of the Black Sea indicates dense coccolith accumulations as a byproduct of the Emiliania huxleyi bloom event. trapped inside the northwestern shelf due to its upstream deflection, productivity within the Anatolian coastal zone and consequently supply into the interior of the western basin rapidly ceases. This was the case observed during the summer of 1998.

SeaWiFS-normalized back radiance data provide new details on the duration, persistence, and spatial extent of the Emiliania huxleyi bloom events in the Black Sea, as well as their connection to circulation dynamics. The data analyzed for the 1997-2000 period (Cokacar et al., 2001) suggest high reflectance patches of E. huxleyi coccolith platelets throughout the basin during the May-July period in each of these years (Figure 7). The cyclonic cell occupying the interior part of the sea is characterized by a relatively stronger signature of water leaving irradiance as compared to the coastal anticyclonic eddies around the periphery. The separation of these two regions with different irradiance characteristics coincides closely with the structure of the Rim Current. Because of its relatively shallow mixed layer thickness, and thus stronger mixed layer average water leaving radiances, the cyclonic cell appears as a favorable site for more intense coccolith blooms relative to the anticyclonic peripheral zone. The presence of a persistent large scale cyclonic circulation system therefore gives the E. huxleyi blooms a basin-wide character in the Black Sea. The contribution of these blooms to increases in the methanesulfonate (MSA) concentrations at two stations along the Turkish and Cretan coastline of the Eastern Mediterranean has recently been pointed out by Kubilay et al. (in press).

The three-dimensional, physical-ecosystem model studies elucidate how the patchiness of phytoplankton blooms is linked with spatial and temporal features of the circulation system. The physical model involves a two and half layer reduced gravity circulation model endowed with active thermodynamics and bulk mixed layer dynamics. It is coupled with a four layer biological model involving a food web structure similar to the one shown in Figure 2 except for the bacterial dynamics. Three of these four layers represent the euphotic zone resolved by the mixed layer at the surface and two intermediate layers below. The fourth layer corresponds to the aphotic part of the water column up to the anoxic interface. As demonstrated by Oguz et al., (2001c), representation of the upper layer water column in the form of four layers can simulate reasonably well the annual phytoplankton biomass structure, consistent with its computationally more demanding multi-level counterpart. The model is able to successfully reproduce major bloom events of the year inferred from the SeaWIFS chlorophyll data as well as available composite in situ measurements performed during the last decade. In particular, the model provides the extended, almost two month-long, autumn and winter phytoplankton blooms, separated from each other by a short period of transition in January (Figure 8). The presence of complex top-down controls operating simultaneously by jellyfish Aurelia and ctenophore Mnemiopsis on heterotrophs and autotrophs is responsible for the presence of such extended autumn-winter bloom events. Eddy-induced lateral transports, asymmetries in the mixed layer depth and its layer-averaged light intensities, together with a complex and highly variable nutrient supply into the euphotic zone controlled by the combination of wind-driven coastal upwelling, eddy-pumping, entrainment due to mixed-layer deepening, and vertical diffusion manifest complex patterns of phytoplankton blooms of both new and regenerated production.

The autumn and the early winter production events begin during late October near the base of the 
euphotic zone (i.e., the third layer) following accumulation of a sufficient amount of nitrate by diffusion and upwelling from the subsurface nitrate pool. Toward the end of November, the subsurface bloom extends to the entire euphotic layer as a result of the convective mixing produced by atmospheric cooling. This bloom event is essentially driven by the upwelling and thus developed preferentially from the cyclonic regions, generally occupying the interior part of the basin. It maintains itself until the first week of January as a result of a continuous supply of nitrate from the subsurface pool as well as its internal recycling inside the euphotic layer. The bloom is then terminated as the phytoplankton stocks are consumed by mesozooplankton. The nutrient supply and recycling however continue throughout January and February. They support another major production event during late February and March once the mesozooplankton grazing pressure is released on phytoplankton due to their predation by gelatinous carnivores, and the mixed layer receives sufficiently strong photosynthetically available solar radiation to trigger primary production. The mixed layer deepens over the euphotic zone everywhere in the basin during the second half of February. Thus, the anticyclones and the peripheral zone of the basin characterized by deeper mixed layers store more nutrients entrained from the chemocline layer, and thus constitute preferential sites for the development of the late winter bloom. The subsequent spring production takes place initially in the mixed-layer and then continues within the subsurface layers after the mixed-layer is depleted in nutrients. They are maintained largely by the regenerated production and gradually loose their intensity toward the summer months. The present version of the coupled physical-ecosystem model serves as a basis to carry out more specific interdisciplinary studies by the regional oceanographic community. 라

\section{Acknowledgements}

This work is a contribution to the Black Sea-ODBMS Project sponsored by the NATO Science for Peace Program. It is supported in part by the NSF Grant OCE9906656 to T. Oguz and P. Malanotte-Rizzoli, OCE9908092 to H. W. Ducklow, and OCE-0081118 to J. W. Murray. T. Oguz also acknowledges the NATO Linkage Grant EST.CLG975821, and the Turkish Scientific and Technical Research Council Grant 101Y005.

\section{References}

Besiktepe, S.T., C.J. Lozano and A.R. Robinson, 2001: On the summer mesoscale variability of the Black Sea. J. Mar. Res., 59, 475-515.

Codispoti, L.A., G.E. Friederich, J.W. Murray and C.M. Sakamoto, 1991. Chemical variability in the Black Sea: implications of continuous vertical profiles that penetrated the oxic/anoxic interface. Deep-Sea Res. I, 38, Suppl.2A, S691-S710.

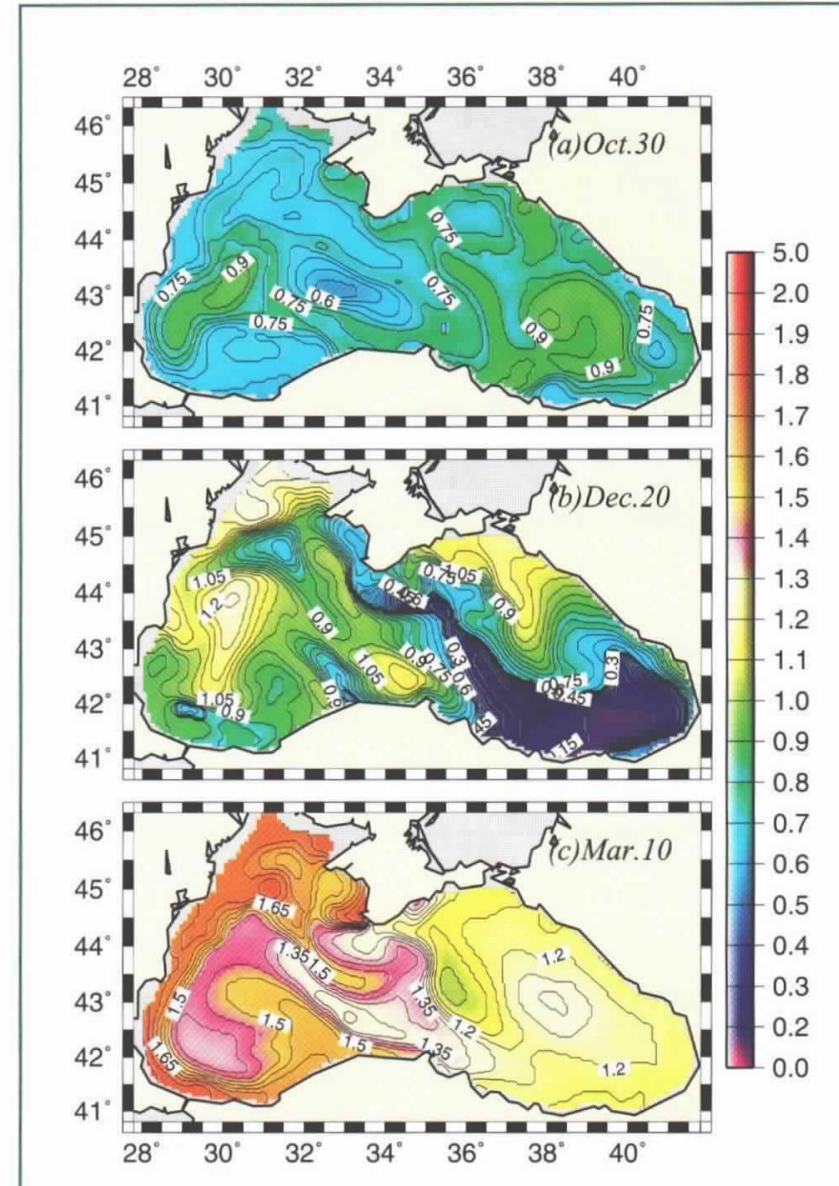

Figure 8. Snapshots of model simulated phytoplankton biomass distributions (in mmol $\mathrm{N} \mathrm{m}^{-3}$ ) at three times of the year corresponding to (a) October 30, (b) December 20, (c) March 10. They represent, respectively, the autumn subsurface, the early winter and the late winterearly spring mixed layer phytoplankton bloom events. Contours are drawn at an interval of $0.05 \mathrm{mmol} \mathrm{N} \mathrm{m}^{-3}$.

Cokacar, T., N. Kubilay and T. Oguz, 2001: Structure of Emiliania huxleyi blooms in the Black Sea surface waters as detected by SeaWIFS imagery. Geophys. Res. Letts., 28(24), 4607-4610.

Kideys, A.E., A.V. Kovalev, G. Shulman, A. Gordina and F. Bingel, 2000: A review of zooplankton investigations of the Black Sea over the last decade. J. Mar. Syst., 24, 355-371.

Konovalov, S.K. and J.W. Murray, 2001: Variations in the chemistry of the Black Sea on a time scale of decades (1960-1995). J. Mar. Syst., 31, 217-243.

Korotaev, G. K., O.A. Saenko and C.J. Koblinsky, 2001: Satellite altimetry observations of the Black Sea level. J. Geophys. Res., 106, 917-933.

Kubilay, N., M. Kocak, T. Cokacar, T. Oguz, G. Kouvarakis and N. Mihalopoulos, in press. The Influence of Black Sea and Local Biogenic Activity on the Seasonal Variation of Aerosol Sulfur Species 
in the Eastern Mediterranean Atmosphere. Global Biogeochem. Cycles.

Mee, L. D., 1992: The Black Sea in crisis: A need for concerted international action. Ambio, 21, 278-286.

Murray, J.W., H.W. Jannash, S. Honjo, R.F. Anderson, W.S. Reeburgh, Z. Top, G.E. Friederich, L.A. Codispoti and E. Izdar, 1989: Unexpected changes in the oxic/anoxic interface in the Black Sea. Nature, 338, 411-413.

Murray, J.W., L.A. Codispoti and G.E. Friederich, 1995: Oxidation-reduction environments: The suboxic zone in the Black Sea. In: Aquatic chemistry: Interfacial and interspecies processes. C.P. Huang, C.R. O'Melia and J.J. Morgan, eds., ACS Advances in Chemistry Series No.224, 157-176.

Oguz, T., 2002: The role of physical processes controlling the Oxycline and Suboxic Layer structures in the Black Sea. Global Biogeochem. Cycles, 16(2), 10.1029/2001GB001465.

Oguz, T., P. La Violette and U. Unluata, 1992: Upper layer circulation of the southern Black Sea: Its variability as inferred from hydrographic and satellite observations. J. Geophys. Res., 97, 12569-12584.

Oguz, T., D.G. Aubrey, V.S. Latun, E. Demirov, L. Koveshnikov, H.I. Sur, V. Diacanu, S. Besiktepe, M. Duman, R. Limeburner and V. Eremeev, 1994: Mesoscale circulation and thermohaline structure of the Black Sea observed during HydroBlack ' 91. Deep-Sea Res. I, 41, 603-628.

Oguz, T., H. Ducklow, P. Malanotte-Rizzoli, S. Tugrul, N. Nezlin and U. Unluata, 1996: Simulation of annualplankton productivity cycle in the Black Sea by a one-dimensional physical-biological model. J. Geophys. Res., 101, 16585-16599.

Oguz, T., H.W. Ducklow, P. Malanotte-Rizzoli, J.W. Murray V.I. Vedernikov and U. Unluata, 1999: A physical-biochemical model of plankton productivity and nitrogen cycling in the Black Sea. DeepSea Res. I, 46, 597-636.

Oguz, T. and S. Besiktepe, 1999: Observations on the Rim Current structure, CIW formation and transport in the western Black Sea. Deep-Sea Res. I, 46, $1733-1753$.

Oguz,T., H.W. Ducklow and P. Malanotte-Rizzoli, 2000: Modeling distinct vertical biogeochemical structure of the Black Sea: Dynamical coupling of the oxic, suboxic and anoxic layers. Global Biogeochem. Cycles., 14, 1331-1352.

Oguz, T., H.W. Ducklow, J. E. Purcell and P. MalanotteRizzoli, 2001a: Modeling the response of top-down control exerted by gelatinous carnivores on the Black Sea pelagic food web. J. Geophys. Res., 106, 4543-4564.

Oguz, T., J. W. Murray, and A.E. Callahan, 2001b: Modeling redox cycling across the suboxic-anoxic interface zone in the Black Sea. Deep-Sea Res. I., 48, 761-787.
Oguz, T., P. Malanotte-Rizzoli and H.W. Ducklow, 2001c: Simulations of phytoplankton seasonal cycle with multi-level and multi-layer physical-ecosystem models: The Black Sea example. Ecological Modelling, 144, 295-314.

Oguz, T., A.G. Deshpande and P. Malanotte-Rizzoli, 2002: On the Role of Mesoscale Processes Controlling Biological Variability in the Black Sea: Inferrences From SeaWiFS-derived Surface Chlorophyll Field. Continental Shelf Res., 22, 1477-1492.

Sur, H.I., E. Ozsoy and U. Unluata, 1994: Boundary current instabilities, upwelling, shelf mixing and eutrophication processes in the Black Sea. Progr. Oceanogr., 33, 249-302.

Tugrul, S., O. Basturk, C. Saydam and A. Yilmaz, 1992: The use of water density values as a label of chemical depth in the Black Sea. Nature, 359, 137-139.

Vinogradov, M.E., E.A. Shushkina, A.S. Mikaelyan and N.P. Nezlin, 1999: Temporal (seasonal and interannual) changes of ecosystem of the open waters of the Black Sea. In: Environmental degradation of the Black Sea: Challenges and Remedies. S.T. Besiktepe, U. Unluata and A.S. Bologa, eds., NATO Sci. Partnership Sub-ser., 2, Vol. 56, Kluwer Academic Publishers, 109-129.

Yilmaz, A., O.A. Yunev, V.I. Vedernikov, S. Moncheva, A.S. Bologa, A. Cociasu and D. Ediger, 1998: Unusual temporal variations in the spatial distribution of chlorophyll-a in the Black Sea during 1990-1996. In: Ecosystem Modeling as a Management Tool for the Black Sea. L. Ivanov and T. Oguz, eds., NATO ASI Series, 2, Vol. 1, Environment-Vol. 47, Kluwer Academic Publishers, 105-120.

Zaitsev, Yu. and V. Mamaev, 1997: Marine Biological Diversity in the Black Sea: A Study of Change and Decline. GEF Black Sea Environmental Programme, United Nations Publications, 208 pp. 